Article

\title{
Biobased Cryogels from Enzymatically Oxidized Starch: Functionalized Materials as Carriers of Active Molecules
}

\author{
Antonella Caterina Boccia ${ }^{1, *(\mathbb{D}, \text { Guido Scavia }}{ }^{1}$, Ilaria Schizzi ${ }^{2}$ and Lucia Conzatti ${ }^{2} \mathbb{C}$ \\ 1 Institute for Chemical Sciences and Technologies-SCITEC “G. Natta”, CNR, Via Corti, 12, 20133 Milano, Italy; \\ guido.scavia@scitec.cnr.it \\ 2 Institute for Chemical Sciences and Technologies-SCITEC “G. Natta”, CNR, Via De Marini, 6, \\ 16149 Genova, Italy; ilaria.schizzi@scitec.cnr.it (I.S.); lucia.conzatti@cnr.it (L.C.) \\ * Correspondence: antonella.boccia@scitec.cnr.it; Tel.: +39-02-236-99-212
}

Academic Editors: Carlos A. García-González, Pasquale Del Gaudio and Ricardo Starbird Received: 20 April 2020; Accepted: 28 May 2020; Published: 31 May 2020

\begin{abstract}
Starch recovered from an agrifood waste, pea pods, was enzymatically modified and used to prepare cryogels applied as drug carriers. The enzymatic modification of starch was performed using the laccase/(2,2,6,6-tetramethylpiperidin-1-yl)oxyl TEMPO system, at a variable molar ratio. The characterization of the ensuing starches by solution NMR spectroscopy showed partial conversion of the primary hydroxyl groups versus aldehyde and carboxyl groups and successive creation of hemiacetal and ester bonds. Enzymatically modified starch after simple freezing and lyophilization process provided stable and compact cryogels with a morphology characterized by irregular pores, as determined by atomic force (AFM) and scanning electron microscopy (SEM). The application of cryogels as carriers of active molecules was successfully evaluated by following two different approaches of loading with drugs: a) as loaded sponge, by adsorption of drug from the liquid phase; and b) as dry-loaded cryogel, from a dehydration step added to loaded cryogel from route (a). The efficiency of the two routes was studied and compared by determining the drug release profile by proton NMR studies over time. Preliminary results demonstrated that cryogels from modified starch are good candidates to act as drug delivery systems due to their stability and prolonged residence times of loaded molecules, opening promising applications in biomedical and food packaging scenarios.
\end{abstract}

Keywords: cryogel; starch; NMR spectroscopy; morphology; drug release

\section{Introduction}

Polysaccharides are natural and environmentally friendly polymers that have been used as starting materials for the production of a "new generation" of biobased materials because they are biocompatible, biodegradable, and nontoxic [1]. Native and modified polysaccharides, such as cellulose [2-5], hemicellulose [6,7], pectin [8,9], polygalactomannans [10-12], starch [13,14], and alginate [15] have been reported as promising matrices for producing bioaerogels via dissolution in water, retrodegradation, solvent exchange, drying via supercritical $\mathrm{CO}_{2}$, and air-liquid phase replacement [1]; and for producing cryogels via conventional lyophilization $[10,11]$. Cryogels are supermacroporous gel networks derived from the cryogelation of monomers or polymeric precursor gel matrices at the subzero temperature. Being lightweight and very resistant to the breakage materials and characterized by interconnected and open porous structures, large surface area, high mechanical strength, and ultralow dielectric constant, they appear suitable for a wide range of applications in several fields [16,17]. Additionally, considering they may be obtained through a simplest approach and in aqueous medium, cryogels are suitable 
and fit for diverse biological and biomedical applications, such as for drug release, immobilization of molecules and cells, and matrices for cell separation [18,19].

The purpose of this paper is to describe the synthesis of modified starch via enzymatic oxidation and the production of cryogels suitable as carriers of active molecules. The oxidation reaction was carried out by using fungal laccase, from Trametes versicolor and the mediator TEMPO (2,2,6,6-tetramethyl-1-piperidinyl-1-oxy radical) at a variable molar ratio [20-22]. Starch from pea pods (Pisum sativum) was used as feedstock derived from an agrifood waste. Starch is a polysaccharide with high molecular weight whose principal components are amylose and amylopectin. Amylose is a linear polymer of D-glucose units linked through $\alpha-(1 \rightarrow 4)$ glycosidic bonds. Amylopectin has a branched structure through both $\alpha-(1 \rightarrow 6)$ and $\alpha-(1 \rightarrow 4)$ glycosidic bonds [23]. The combined use of laccase enzyme and the mediator TEMPO is a well-known method for the suitable oxidation of the primary hydroxyl groups to aldehydes [24,25]. The consequential formation of hemiacetalic bonds between the newly formed carbonyl and carboxyl groups and the free hydroxyl groups supports the creation of a crosslinked network responsible for the modified material behavior and allows the modulation of the material properties [25]. After the oxidation reaction, the modified starches were thoroughly characterized by mono- and two-dimensional solution NMR spectroscopy to determine the degree of oxidation and the nature of newly formed functional groups. Applying a conventional lyophilization process to modified starch, cryogels were obtained, and the morphology was investigated using atomic force microscopy (AFM) and SEM. The sorption/desorption capability of the cryogels was evaluated using caffeine in water, chosen as a "model drug" for the presence of functional groups in the molecular structure able to interact with those on starch polymer chains, thus favoring a slower desorption phenomenon. Moreover, this being a molecule that is a natural antioxidant by scavenging hydroxyl radicals, it is appropriate for biomedical applications to support the use of the proposed carrier [26]. Two different approaches of cryogel loading were evaluated, as reported: (a) adsorption of caffeine from the liquid phase (sponge cryogel); and (b) adsorption of caffeine from the liquid phase followed by a dehydration process (dry-loaded cryogel). Profile studies of release were then conducted by collecting a series of proton NMR spectra over time, thus showing encouraging preliminary results for the use as carriers. Synthesized cryogels, due to their properties, could have a wide range of promising applications in biomedicine (immobilizing biomolecules; capturing target molecules; for drug delivery; for wound healing), biotechnology, and bioseparation segments.

\section{Results}

\subsection{Starch Oxidation}

Purified starch from pea pod powder was enzymatically oxidized by using fungal laccase and the mediator TEMPO in mild reaction conditions and at a variable molar ratio (see Table 1), as described in Section 4.2.

Table 1. Reaction conditions for the TEMPO-mediated laccase oxidation of PS in water.

\begin{tabular}{cccc}
\cline { 2 - 3 } Sample & TEMPO $(\mathbf{m g})$ & Laccase $^{\mathbf{1}} \mathbf{( \mathbf { m g } )}$ \\
\hline $\mathrm{A}$ & 1 & 4 \\
$\mathrm{~B}$ & 1 & 40 \\
$\mathrm{C}$ & 10 & 40 \\
${ }^{1}$ Laccase was dissolved in $1 \mathrm{~mL}$ of water prior use. ${ }^{2}$ Sample D was not enzymatically oxidized.
\end{tabular}

Trametes versicolor was chosen as a source of laccase because its carboxyl content was the largest compared to that of other enzymes [27] and because it is able to promote the oxidation of the mediator TEMPO in an unbuffered water medium. During oxidation, the mediator TEMPO is converted into an oxonium ion, able to selectively act on the primary hydroxyl groups present on pea pod starch 
(PS) chains, thus generating aldehyde groups. The chemical nature of PS derivatives was deeply investigated by mono- and two-dimensional NMR spectroscopy. Results were perfectly in line with the literature data, supporting experimentally the occurrence of the oxidation in low yield $(10 \%)$ as observed for other polysaccharides, such as polygalactomannans [25] arabinoxylan and konjac glucomannans [10], for which a maximum of $12 \%$ of oxidation degree was reached. As a consequence, the resonances of the partially oxidized PS, in the proton spectrum of Figure 1, have small intensities overlapping with those of the native PS. The obtainment of aldehyde derivatives was confirmed by the appearance in the proton spectrum of characteristic resonances at 9.23 and $9.28 \mathrm{ppm}$ in the ${ }^{1} \mathrm{H}$ spectrum of Figure 1. Moreover, ${ }^{1} \mathrm{H}$ chemical shifts of partially oxidized PS were assigned and are listed in Table S1 according to available literature data and two-dimensional experiments. Some peculiar signals in the proton spectrum were very close to those reported for acetylated starches $[28,29]$ and oxidized polygalactomannans $[24,25]$.

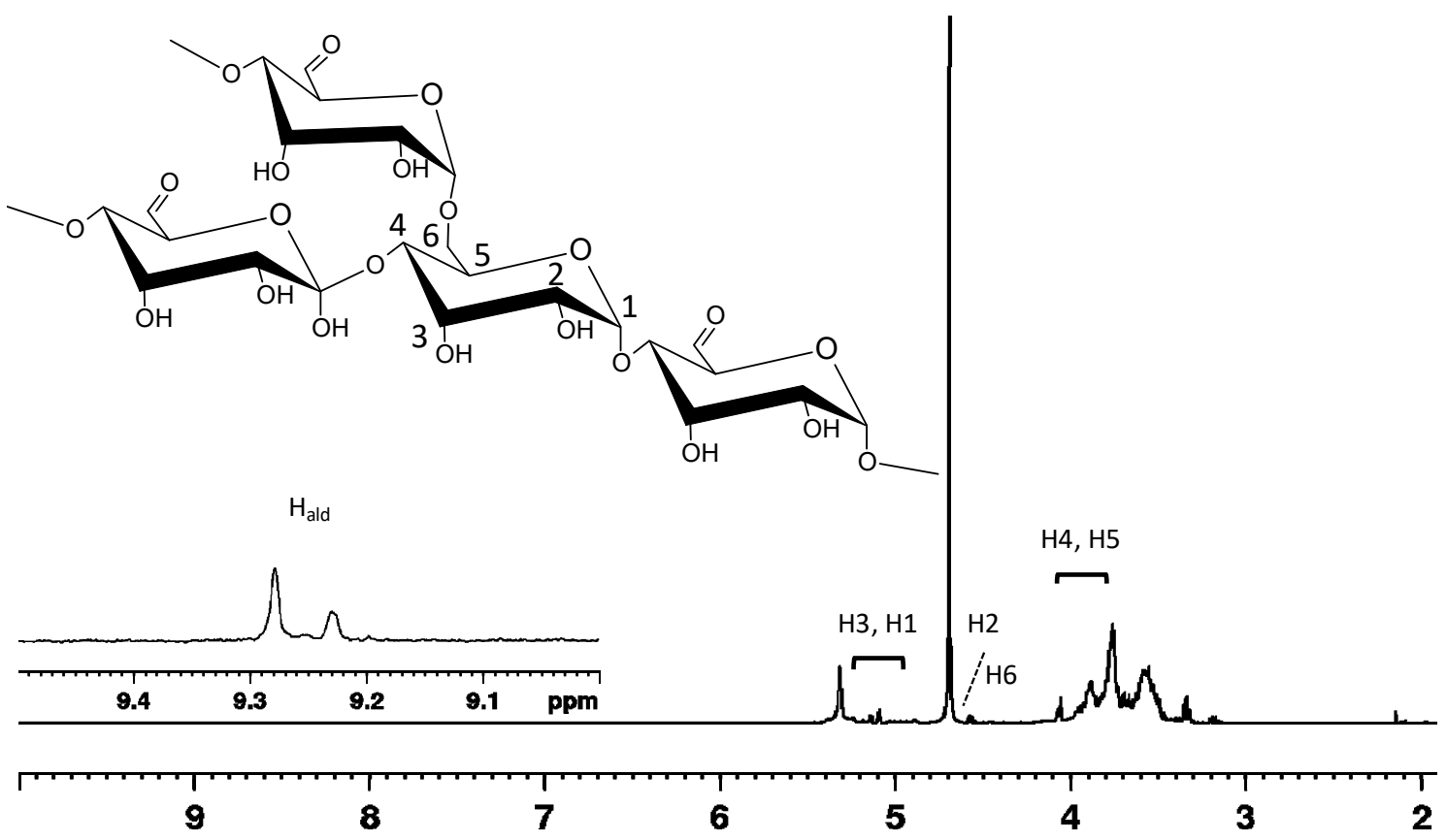

Figure 1. ${ }^{1} \mathrm{H}$ NMR spectrum of partially oxidized pea starch (sample C), recorded at $298 \mathrm{~K}$, in $\mathrm{D}_{2} \mathrm{O}$ (for simplicity, only the numbering scheme of the amylopectin derivative is illustrated; the assignment refers to partially oxidized starch).

In the ${ }^{13} \mathrm{C}$ spectrum of partially oxidized PS in Figure S3, the signals of produced acid residues are scarcely detectable because of the low yield of the oxidization reaction and especially the absence of NOE signal enhancement together with a long relaxation delay. In addition, the carbonyl signal expected in the 190-200 ppm region in the ${ }^{13} \mathrm{C}$ spectrum cannot be easily detected, thus indicating that the aldehyde groups are hydrated or forming hemiacetals with the hydroxyl groups [30]. Nevertheless, the formation of a carboxyl carbon derivative for the modified PS was confirmed by the HMBC spectrum in Figure 2; this is because of the major sensitivity of the experiment along the proton dimension. Analyzing in detail the carboxyl region in Figure 2 (at $170-190$ ppm), it is possible to observe a cross peak at $177.9 \mathrm{ppm}$ referring to a ${ }^{3} \mathrm{~J}_{\mathrm{CH}}$ correlation of a proton at $4.1 \mathrm{ppm}$ with the carboxyl atom. This cross peak was assigned to the newly formed carboxyl group at the C6 position of the modified PS correlating through three bonds with the H4 proton. The enhanced technique also allowed easier detection of minor peaks attributable to the partially oxidized PS. Indeed, signals related to hemiacetalic derivatives were revealed from the HMBC analysis (at ca. 80-90 ppm), in agreement with literature data $[25,30,31]$ and confirming the ${ }^{13} \mathrm{C}$ NMR data. These derivatives can be justified 
from the chemo-enzymatic oxidation mechanism that supports the creation of a crosslinked network between the newly formed carbonyl and free hydroxyl groups. These groups are able to form intraand inter-chain hemiacetalic bonds that are finally responsible for the modified material behavior.

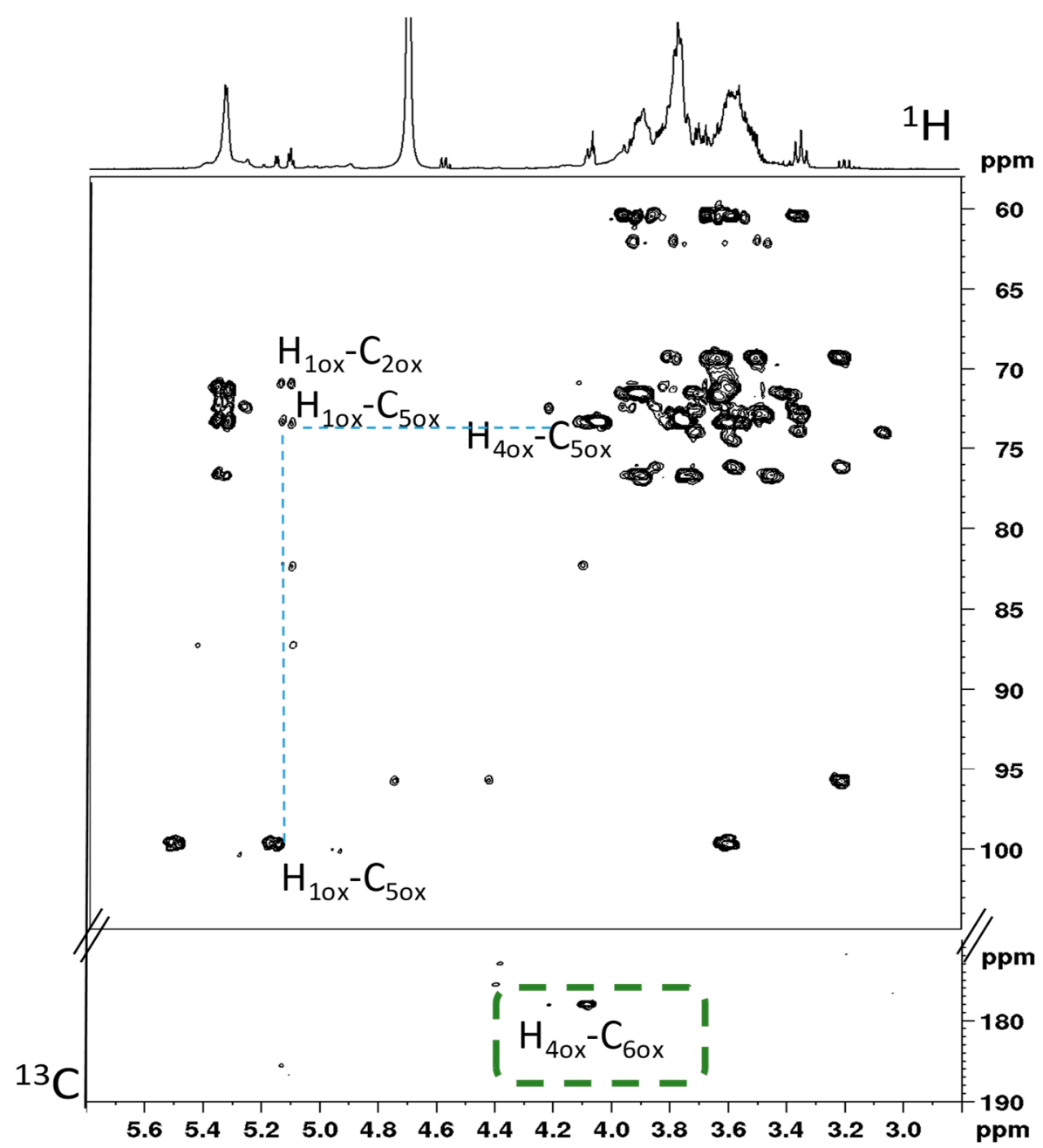

Figure 2. ${ }^{1} \mathrm{H}-{ }^{13} \mathrm{C}$ HMBC spectrum of partially oxidized pea pod starch (PS) from sample $\mathrm{C}$ in $\mathrm{D}_{2} \mathrm{O}$ at $298 \mathrm{~K}$. Some characteristic resonances are highlighted and refer to minor components from the oxidation process assigned with this technique.

Finally, the entire spin system was verified by $2 \mathrm{D}^{1} \mathrm{H}-{ }^{1} \mathrm{H}$ double quantum filtered-total correlation spectroscopy (TOCSY) experiment reported in Figure S4.

\subsection{Cryogels}

The final recovered cryogels from the modified PSs, obtained as illustrated on Section 4.2, showed different structures depending on the mediator TEMPO/laccase ratio in Table 1; therefore, samples A and B both showed fragile textures as fluffy and easy water dispersible matrices (sample B in Figure 3a); by contrast, sample $C$ evidenced a compact and reinforced structure, as shown in Figure $3 b$. 
a)

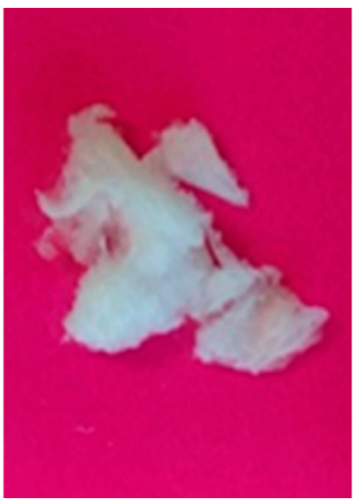

b)

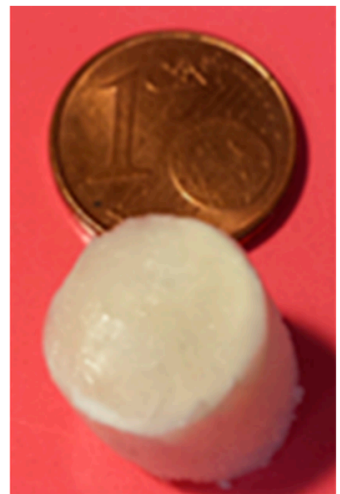

Figure 3. Cryogels from the modified PS as obtained from variable 2,2,6,6-tetramethyl-1-piperidinyl-1oxy radical (TEMPO)/laccase ratio as shown in Table 1: (a) sample B; (b) sample C.

\section{Cryogel Morphology}

SEM analysis on sample $C$ in Figure 4 shows a highly porous structure, with the dimension of pores appearing to be not homogeneous in the whole fragile fractured surface. Indeed, areas with both smaller and bigger pores are observed. Moreover, nanometric holes are visible within some walls.
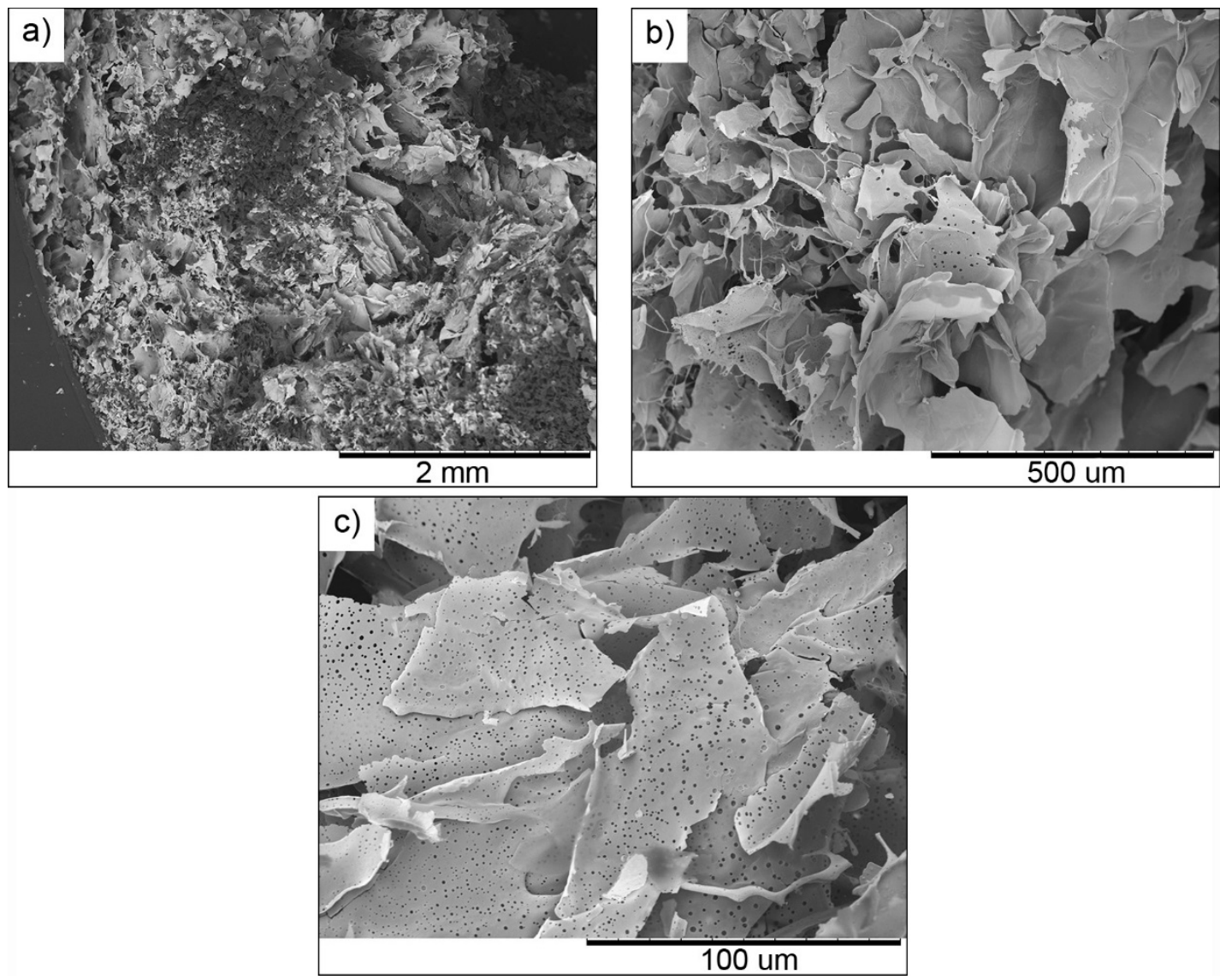

Figure 4. SEM images at different magnifications of the fragile fractured surface of sample C.

The morphological analysis carried at higher magnification by AFM in Figure 5 confirmed the presence of pores heterogeneously shaped and sized, of which the smallest ones range from approximately $200 \mathrm{~nm}$ to a few microns. Grain morphology of the flat areas (inlet of Figure 5b) was also evidenced. 
a)

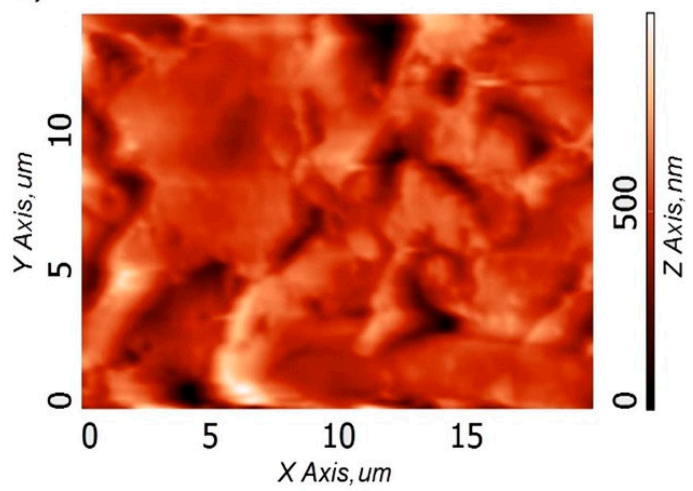

b)

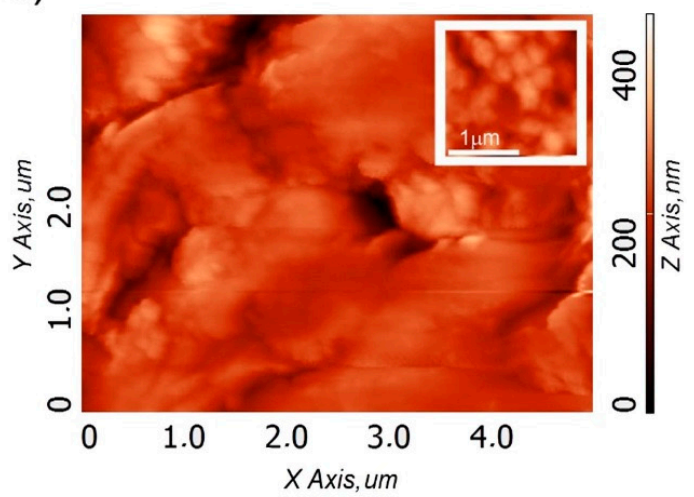

Figure 5. Atomic force microscopy (AFM) images of the sample C cryogel surface at: lower (a) and higher (b) magnifications. The inlet in (b) represents a magnification of the flat area.

This morphology with heterogeneously shaped pores is similar to that reported for superabsorbent aerogels obtained from cellulose nanofibrils [32,33] and hydrogels for tissue regeneration [34]. The presence of pores heterogeneous in shape and size together with nanometric pores in the walls could be useful for tuning the absorption/release of active molecules, such as caffeine.

\section{Discussion}

\section{Cryogels as Carrier}

The ability of the partially modified PS to act as a delivery system of active molecules was investigated by solution NMR spectroscopy, as this technique is not limited to specific classes of compounds or functional groups but can be extended to the determination of all hydrocarbon compounds and is very useful for the analysis of mixture. Moreover, together with the release profile, it is possible to observe when the cryogel starts to dissolve. Finally, it is a quantitative and non-disruptive technique.

To test the cryogels' ability to act as drug carrier, caffeine was chosen as model molecule because of the affinity of its functional groups with those of modified PS and because it is a well-known antioxidant and pro-oxidant and has reinforcing properties [35]. All samples in Table 1 were loaded with caffeine by immersing each of them into an Eppendorf tube containing caffeine in water, as illustrated in Section 4.3. (route (a)), and finally, samples A and B were discarded because of their fragile texture and easy water solubility; thus, cryogels from sample $C$ conditions were used like carriers due to their compact and sTable Structure. Successively, the uploading capacity was evaluated for both samples. The main difference between the two loading methods is in the wet or dry use of the cryogels. For wet uses, the idea is to enhance the dissolution rate of poorly water-soluble drugs, thus increasing the therapeutic effects linked to drug availability. In the case of dry-loaded cryogels, wound healing applications are considered. This cryogel may be able to generate a wet gel at the wound site when an exudate is present, thus avoiding perilesional skin damages.

Firstly, for sponge cryogels from route (a), the release profiles of adsorbed caffeine were evaluated by collecting a series of proton NMR experiments acquired as detailed in Section 4.5. Direct quantification of released caffeine was done through a proportional comparison between the signal of the internal standard (TMS at $\delta=0 \mathrm{ppm}$ ) and a selected signal of caffeine (e.g., a methyl signal at $\delta=3.32 \mathrm{ppm}$,) considering that in a proton spectrum, the area of the signals is directly proportional to the number of protons present in the active volume of the sample [36]. Milligrams of released caffeine were determined by applying Equation (1) and then plotted vs. contact time in Figure 6 (considering cumulative milligrams over time). Data analysis for the sponge cryogel evidenced that the maximum of released caffeine was reached in the first 1560 min of elution, probably due to the quick release of caffeine from the surface of the PS material. Successively, for more prolonged contact time, the concentration 
goes down, and a more constant profile was reached probably because the caffeine entrapped in the core system was slowly released over time. After prolonged contact time, the cryogel starts to dissolve. Two stock solutions were analyzed to replicate data showing the same trend.

In the case of the dry-loaded cryogel from route (b), the procedure for the quantitative analysis of released caffeine was the same as described above. The plot of NMR data vs. contact time in Figure 6 evidenced no significant differences on the release profile for this material with respect to the sponge cryogel. The only valuable difference is attributable to the stability of this material that is more fragile and difficult to handle. In addition, in this case, two stock solutions were analyzed to replicate data showing the same trend.

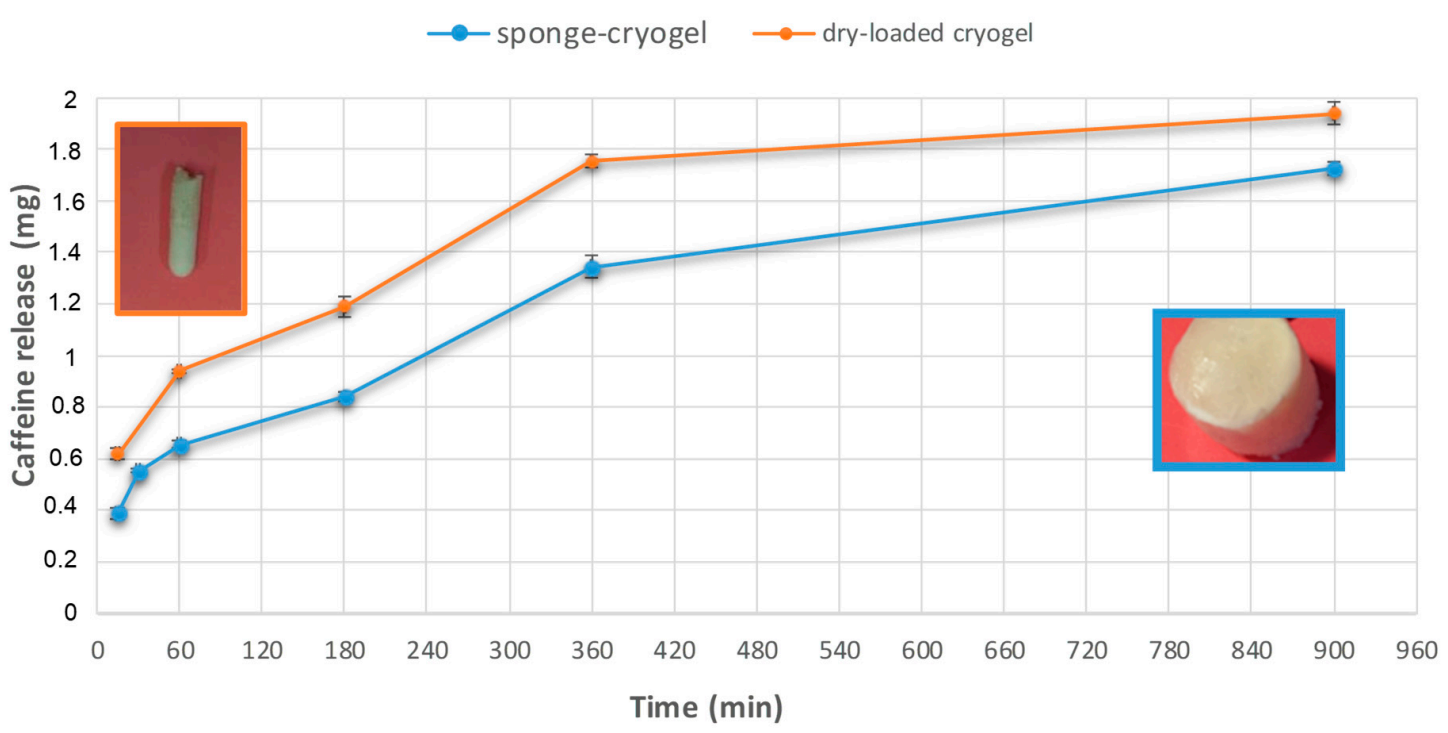

Figure 6. Percentage/mg medium values of the cumulative caffeine release versus time (standard deviation bars are reported) for the sponge cryogel and dry-loaded sample.

These preliminary studies are encouraging and aspire to develop cryogels for specific applications. The sponge cryogels may contribute to the development of specific administration routes (topical, pulmonary, oral), thus shaping on demand, and on the "site" the drug availability. The dry-loaded cryogel will be useful for wound healing applications; it will mimic the natural tissue environment, and when loaded with antioxidant molecules, it can enhance antibiotic resistance during bacterial invasion [37].

\section{Materials and Methods}

\subsection{Materials}

Starch from pea pods (PS) in powder was generously provided by Dr. Marco Radice of Emsland Group and used after purification, carried out by dispersing it (10\% w/w) in MilliQ water and ethanol in a 60/40 ratio by stirring at room temperature for $1 \mathrm{~h}$. The material was recovered by filtration and then dispersed at $10 \% w / w$ in acetone and stirred for an additional hour at room temperature. After vacuum filtration, the material was dried at $50{ }^{\circ} \mathrm{C}$ overnight. The final yield was $94 \%(w / w)$.

Laccase from Trametes versicolor in powder form $(0.5 \mathrm{U} / \mathrm{mg}$ as declared by Sigma-Aldrich), mediator TEMPO, caffeine, and all other chemicals were purchased from Sigma-Aldrich (Sigma-Aldrich, Darmstadt, Germany) and used as received. Deuterated water, $\left(\mathrm{D}_{2} \mathrm{O}\right.$ 99.9\%), and tetramethylsilane (TMS) for NMR spectroscopy were purchased from CortecNet (CortecNet, Les Ulis France) and used as received. 


\subsection{Oxidation Process and Cryogel Preparation}

Purified PS was dispersed in milliQ water and stirred for $1 \mathrm{~h}$ at room temperature and then left overnight without stirring. Successively, a suspension of PS $(10 \mathrm{mg})$ in water $(2 \mathrm{~mL})$ was prepared and stirred for $30 \mathrm{~min}$ at $30^{\circ} \mathrm{C}$, and then the mediator TEMPO and laccase were added in a molar ratio as reported in Table 1 . The reaction mixture was stirred for $4 \mathrm{~h}$ at $30^{\circ} \mathrm{C}$ and then kept at room temperature overnight. Finally, the enzyme was inactivated by placing the reactor into a boiling bath for $15 \mathrm{~min}$.

The so-obtained reaction mixture, slightly viscous, was kept frozen at $8-0^{\circ} \mathrm{C}$ for $18 \mathrm{~h}$ in cylindrical reactors and then lyophilized at $-55^{\circ} \mathrm{C}$ for $24 \mathrm{~h}(0.03$ mbar). Recovered samples after lyophilization were stored at room temperature. Syntheses were duplicated to verify the reaction reproducibility. Furthermore, to verify the possibility of generating cryogels from the not enzymatically oxidized PS, the freeze-drying procedure was applied to a suspension of PS (10 mg) in water $(2 \mathrm{~mL})$ (sample D in Table 1) obtaining no cryogel.

\subsection{Caffeine Adsorption in the Cryogel Structure}

The adsorption of caffeine in cryogel was carried out following two different procedures, as follows: (a) for the sponge cryogel, a slice of $15 \mathrm{~mm}$ in diameter $(5 \div 6 \mathrm{mg}$ ), obtained from sample $\mathrm{C}$ (in Table 1 ), was immersed into an Eppendorf tube containing caffeine in water $(5 \mathrm{mM})$ for $90 \mathrm{~min}$, then washed with $500 \mu \mathrm{L}$ of water, and weighted to determine the "uploading capacity"; (b) the cryogel from route (a), after being charged with caffeine in water, was re-lyophilized, giving rise to the dry-loaded cryogel. Both procedures utilized the cryogel obtained from sample $C$ condition in Table 1 because it is more stable in water with respect to samples A and B.

\subsection{Studies on Sorption/Desorption of Caffeine in the Cryogels}

The sorption/desorption capability of the loaded cryogel from route (a) was evaluated by immersing it into $700 \mu \mathrm{L}$ of fresh deuterated water at regular interval time (respectively for 15, 30, 60, 180, 240, and $900 \mathrm{~min}$ as contact time) before acquisition of the NMR data. For all recovered solutions, proton spectra were recorded in quantitative conditions to evaluate the amount of released caffeine over time, and then this parameter was plotted as function of time considering the cumulative amount.

The sorption/desorption capability for the dry-loaded cryogel from route (b) was determined as detailed above by immersing it into $700 \mu \mathrm{L}$ of fresh deuterated water at regular interval time, and proton NMR experiments were conducted on each solution. Finally, data were evaluated over time. Data were duplicated in both cases.

The experimental scheme illustrating the sorption/desorption procedure in the cryogels is reported in Figure S1.

\subsection{NMR Spectroscopy}

Mono- and two-dimensional NMR experiments were recorded on a 500-MHz Bruker DMX spectrometer, operating at $11.7 \mathrm{~T}$, equipped with a $5 \mathrm{~mm}$ probe and gradient unit on $\mathrm{z}$, and thermostated at $298 \mathrm{~K}$ (Bruker Biospin $\mathrm{GmbH}$, Rheinstetten, Karlsruhe, Germany). The samples were prepared by dissolving $5.0 \mathrm{mg}$ of oxidized starch into $700 \mu \mathrm{L}$ of $\mathrm{D}_{2} \mathrm{O}$ at room temperature (The NMR data were acquired on modified PS before the lyophilization process, and no precipitate or solid materials was observed in the NMR tube.). As internal standard, $20 \mu \mathrm{L}$ of a $0.7 \mathrm{mM}$ TMS/water solution was added to each NMR solution before data acquisition.

Acquisition parameters for ${ }^{1} \mathrm{H}$ experiments of enzymatically oxidized pea starch: $90^{\circ}$ pulse $9.75 \mu \mathrm{s}$; PL1-2.2 dB; relaxation delay, $20.0 \mathrm{~s}$. Spectral width, $8400 \mathrm{~Hz}$; number of transient, 1024.

${ }^{13} \mathrm{C}$ parameters: spectral width, $14 \mathrm{KHz}, 90^{\circ}$ pulse, $11.0 \mu \mathrm{s}$; PL1-1.3 dB with a delay of $10 \mathrm{~s}$.

2D ${ }^{1} \mathrm{H}^{1}{ }^{1} \mathrm{H}$ DQF-TOCSY (double quantum filtered-total correlation spectroscopy) was acquired with 256 experiments over $2 \mathrm{~K}$ data points and 256 scans each, with a mixing time of $0.09 \mathrm{~s}$ and a relaxation delay of $1.2 \mathrm{~s}$. 
The $2 \mathrm{D}^{1} \mathrm{H}-{ }^{13} \mathrm{C}$ g-HSQC experiments (gradient-heteronuclear single quantum coherence) were performed by applying a coupling constant ${ }^{1} J_{\mathrm{CH}}=150 \mathrm{~Hz}$; data matrix $2 \mathrm{~K} \times 256$; number of scans: 128 .

The $2 \mathrm{D}^{1} \mathrm{H}-{ }^{13} \mathrm{C}$ g-HMBC experiments (gradient-heteronuclear multiple bond correlation) were performed by applying a delay of $50 \mathrm{~ms}$ for the evolution of long-range coupling; data matrix $2 \mathrm{~K} \times 256$; number of scans 128; D1 $2.00 \mathrm{~s}$. Data were zero filled and weighted with a sine bell function before Fourier transformation.

Quantitative acquisition parameters for ${ }^{1} \mathrm{H}$ spectra of caffeine solutions: $90^{\circ}$ pulse, $9.75 \mu \mathrm{s}$; PL1-2.2 dB; relaxation delay, $40.0 \mathrm{~s}$. Spectral width, $8400 \mathrm{~Hz}$; number of transient, 1024. Data processing: exponential line broadening of $0.1 \mathrm{~Hz}$ was applied as resolution enhancement function; zero-filling to $32 \mathrm{~K}$ prior FT (TopSpin 4.0.6 software, Bruker Biospin $\mathrm{GmbH}$, Rheinstetten, Karlsruhe, Germany). Spectra were referenced to the residual solvent signal of TMS at $\delta=0 \mathrm{ppm}$, as internal standard.

For all experiments, spectra phasing and integration were performed manually, and the NMR spectra were processed using the Bruker TopSpin 4.0.6 software (Bruker Biospin GmbH, Rheinstetten, Karlsruhe, Germany).

Caffeine content was determined from the integral value in the proton spectrum by applying Equation (1) [36]:

$$
[\mathrm{mM}] \mathrm{c}=\mathrm{Ic} / \mathrm{Hc}[\mathrm{mM}] \mathrm{st} \text { Hst/Ist }
$$

where $[\mathrm{mM}] \mathrm{c}$ is the millimolar concentration of caffeine; $[\mathrm{mM}] \mathrm{st}$ is the millimolar concentration of the standard solution of TMS; Ic, Ist, and Hc and Hst are the integral value and number of protons generating the signals of caffeine and TMS, respectively. The ${ }^{1} \mathrm{H}$ spectrum of caffeine with resonance assignment is reported in Figure S2.

\subsection{Cryogel Morphology}

The morphology and structure of the samples were assessed using scanning electron microscopy (SEM) performed on a Hitachi TM 3000 Benchtop SEM instrument (Tokyo, Japan) operating at $15 \mathrm{kV}$ acceleration voltage. Observations were carried out on fragile fractures (in liquid nitrogen) of samples lyophilized and sputter-coated with gold.

Observations at higher magnification were carried out with a commercial AFM (NTMDT) model NTEGRA in tapping mode. For AFM measurements, the oxidized PS sample was fixed on a glass slide with a double tape.

\section{Conclusions}

Sustainable and renewable starch-based cryogels have been synthesized from enzymatically modified starch from pea pods, combined with conventional lyophilization. The nature of the functional groups derived from the oxidation reaction seems to play a crucial role in affecting the final behavior and properties of the synthesized materials. This work highlights the role of NMR spectroscopy as an analytical tool for material characterization and determination of the drug release profile of cryogels, allowing at the same time, to follow the material degradation process. The ability of the prepared cryogels to act as drug carriers might be useful in designing novel bio-inspired materials with promising application for wound healing and for specific administration routes in the pharmacological field. In the future, antimicrobial effects will be investigated to improve the performance of cryogels and to open the scenario on novel applications.

Supplementary Materials: The following are available online: Figure S1. Experimental scheme illustrating the procedure for sorption/desorption of caffeine. Figure S2. ${ }^{1} \mathrm{H}$ spectrum of caffeine with resonance assignment. Figure S3. ${ }^{13} \mathrm{C}$ NMR spectrum of oxidized PS (sample C), recorded at $298 \mathrm{~K}$, in $\mathrm{D}_{2} \mathrm{O}$. Figure S4. TOCSY spectrum of oxidized PS (sample C), recorded at $298 \mathrm{~K}$, in $\mathrm{D}_{2} \mathrm{O}$. Table S1. Peculiar chemical shifts for ${ }^{1} \mathrm{H}$ species of modified PS.

Author Contributions: Conceptualization, A.C.B.; methodology, A.C.B.; characterization, A.C.B., G.S., I.S., and L.C.; writing-original draft preparation, A.C.B. and L.C.; investigation, data analysis, writing-review and editing, A.C.B., G.S., and L.C. All authors have read and agreed to the published version of the manuscript. 
Funding: This research received no external funding.

Acknowledgments: Authors are grateful to Alberto Giacometti Schieroni for technical support.

Conflicts of Interest: The authors declare no conflict of interest.

\section{References}

1. García-González, C.A.; Budtova, T.; Durães, L.; Erkey, C.; DelGaudio, P.; Gurikov, P.; Koebel, M.; Liebner, F.; Neagu, M.; Smirnova, I. An Opinion Paper on Aerogels for Biomedical and Environmental Applications. Molecules 2019, 24, 1815. [CrossRef] [PubMed]

2. Gavillon, R.; Budtova, T. Aerocellulose: New highly porous cellulose prepared from cellulose-NaOH aqueous solutions. Biomacromolecules 2008, 9, 269-277. [CrossRef] [PubMed]

3. Aaltonen, O.; Jauhiainen, O. The preparation of lignocellulosic aerogels from ionic liquid solution. Carbohyd. Polym. 2009, 75, 125-129. [CrossRef]

4. Aulin, C.; Netrval, J.; Wagberg, L.; Lindstrom, T. Aerogels from nanofibrillated cellulose with tunable oleophobicity. Soft Matter 2010, 6, 3298-3305. [CrossRef]

5. Heath, L.; Thielemans, W. Cellulose nanowhisker aerogels. Green Chem. 2010, 12, 1448-1453. [CrossRef]

6. Zhang, W.; Zhang, Y.; Lu, C.; Deng, Y. Aerogels from crosslinked cellulose nano/micro-fibrils and their fast shape recovery property in water. J. Mater. Chem. 2012, 22, 11642-11650. [CrossRef]

7. Mingjie, C.; Xueqin, Z.; Aiping, Z.; Chuanfu, L.; Runcang, S. Direct preparation of green and renewable aerogel materials from crude bagasse. Cellulose 2016, 23, 1325-1334.

8. Sila, D.N.; Van Buggenhout, S.; Duvetter, T.; Fraeye, I.; De Roeck, A.; Van Loey, A.; Hendrickx, M. Pectins in processed fruits and vegetables: Part II-Structure-function relationship. Compr. Rev. Food Sci. Food Saf. 2009, 8, 86-104. [CrossRef]

9. Rudaz, C.; Courson, R.; Bonnet, L.; Calas-Etienne, S.; Sallée, H.; Budtova, T. Aeropectin: Fully Biomass-Based Mechanically Strong and Thermal Superinsulating Aerogel. Biomacromolecules 2014, 15, 2188-2195. [CrossRef]

10. Parikka, K.; Nikkila, I.; Pitkanen, L.; Ghafar, A.; Sontag-Strohm, T.; Tenkanen, M. Laccase/TEMPO oxidation in the production of mechanically strong arabinoxylan and glucomannan aerogels. Carbohyd. Polym. 2017, 175, 377-386. [CrossRef]

11. Ponzini, E.; Natalello, A.; Usai, F.; Bechmann, M.; Peri, F.; Muller, N.; Grandori, R. Structural characterization of aerogels derived from enzymatically oxidized galactomannas of fenugreek, sesbania and guar gums. Carbohyd. Polym. 2019, 207, 510-520. [CrossRef] [PubMed]

12. Cerqueira, M.A.; Bourbon, A.I.; Pinheiro, A.C.; Martins, J.T.; Souza, B.W.; Teixeira, J.A.; Vicente, A.A. Galactomannans use in the development of edible films/coatings for food applications. Trends Food Sci. Technol. 2011, 22, 662-671. [CrossRef]

13. Druel, L.; Bardl, R.; Vorwerg, W.; Budtova, T. Starch aerogels: A member of the family of thermal superinsulating materials. Biomacromolecules 2017, 18, 4232-4239. [CrossRef] [PubMed]

14. Kenar, J.A.; Eller, F.J.; Felker, F.C.; Jackson, M.A.; Fanta, G.F. Starch aerogel beads obtained from inclusion complexes prepared from high amylose starch and sodium palmitate. Green Chem. 2014, 16, 1921-1930. [CrossRef]

15. Quraishi, S.; Martins, M.; Barros, A.A.; Gurikov, P.; Raman, S.P.; Smirnova, I.; Duarte, A.R.C.; Reis, R.L. Novel non-cytotoxic alginate-lignin hybrid aerogels as scaffolds for tissue engineering. J. Supercrit. Fluids 2015, 105, 1-8. [CrossRef]

16. Sescousse, R.; Gavillon, R.; Budtova, T. Aerocellulose from cellulose-ionic liquid solutions: Preparation, properties and comparison with cellulose- $\mathrm{NaOH}$ and cellulose-NMMO routes. Carbohydr. Polym. 2011, 83, 1766-1774. [CrossRef]

17. Buchtova, N.; Budtova, T. Cellulose aero-, cryo-and xerogels: Towards understanding of morphology control. Cellulose 2016, 23, 2585-2595. [CrossRef]

18. Bakhshpour, M.; Idil, N.; Perçin, I.; Denizli, A. Biomedical Applications of Polymeric Cryogels. Appl. Sci. 2019, 9, 553. [CrossRef]

19. Nayak, A.K.; Das, B. Introduction to polymeric gels. In Polymeric Gels; Woodhead Publishing: Cambridge, UK, 2018; Volume 6, pp. 3-27. [CrossRef] 
20. Ghafar, A.; Gurikov, P.; Subrahmanyam, R.; Parikka, K.; Tenkanen, M.; Smirnova, I.; Mikkonen, K. Mesoporous guar galactomannan based biocomposite aerogels through enzymatic crosslinking. Compos. A 2017, 94, 93-103. [CrossRef]

21. Lavazza, M.; Formantici, C.; Langella, V.; Monti, D.; Pfeiffer, U.; Galante, Y.M. Oxidation of galactomannan by laccase plus TEMPO yields an elastic gel. J. Biotechnol. 2011, 156, 108-116. [CrossRef]

22. Leppanen, A.S.; Niittymaki, O.; Parikka, K.; Tenkanen, M.; Eklund, P.; Sjoholm, R.; Willfor, S. Metal-mediated allylation of enzymatically oxidized methyl $\alpha$-D-galactopyranoside. Carbohydr. Res. 2010, 345, 2610-2615. [CrossRef]

23. Tester, R.F.; Karkalas, J.; Qi, X. Starch-Composition, fine structure and architecture. J. Cereal Sci. 2004, 39, 151-165. [CrossRef]

24. Parikka, K.; Tenkanen, M. Oxidation of methyl alpha-D-galactopyranoside by galactose oxidase: Products formed and optimization of reaction conditions for production of aldehyde. Carbohydr. Res. 2009, 344, 14-20. [CrossRef] [PubMed]

25. Merlini, L.; Boccia, A.C.; Mendichi, R.; Galante, Y.M. Enzymatic and chemical oxidation of polygalactomannans from the seeds of a few species of leguminous plants and characterization of the oxidized products. J. Biotechnol. 2015, 198, 31-43. [CrossRef] [PubMed]

26. Daly, J.W.; Butts-Lamb, P.; Padgett, W. Subclasses of adenosine receptors in the central nervous system: Interaction with caffeine and related methylxanthines. Cell. Mol. Neurobiol. 1983, 3, 69-80. [CrossRef]

27. Sindhu, M.; Adlercreutz, P. Mediator facilitated, laccase catalysed oxidation of granular potato starch and the physico-chemical characterisation of the oxidized products. Bioresour. Technol. 2009, 100, 3576-3584.

28. Chi, H.; Xu, K.; Wu, X.; Chen, Q.; Xue, D.; Song, C.; Zhang, W.; Wang, P. Effect of acetylation on the properties of corn starch. Food Chem. 2008, 106, 923-928. [CrossRef]

29. Gidley, M.J. Observations on N.M.R. spectra of starches in dimethyl sulfoxide, iodine-complexing, and solvation in water-di-methyl sulfoxide. Carbohydr. Res. 1985, 139, 85-93. [CrossRef]

30. Wu, X.; Ye, Y.; Chen, Y.; Ding, B.; Cui, J.; Jiang, B. Selective oxidation and determination of the substitution pattern of hydroxypropyl guar gum. Carbohydr. Polym. 2010, 80, 1178-1182. [CrossRef]

31. Kato, Y.; Matsuo, R.; Isogai, A. Oxidation process of water-soluble starch in TEMPO-mediated system. Carbohydr. Polym. 2003, 51, 69-75. [CrossRef]

32. Jimenez-Saelices, C.; Seantier, B.; Cathala, B.; Grohens, Y. Sprayfreeze-dried nanofibrillated cellulos eaerogels with thermal superinsulating properties. Carbohydr. Polym. 2017, 157, 105-112. [CrossRef] [PubMed]

33. Jianga, F.; Hsieh, Y. Amphiphilic superabsorbent cellulose nanofibril aerogels. J. Mater. Chem. A 2014, 2, 6337-6342. [CrossRef]

34. Stagnaro, P.; Schizzi, I.; Utzeri, R.; Marsano, E.; Castellano, M. Alginate-polymethacrylate hybrid hydrogels for potential osteochondral tissue regeneration. Carbohydr. Polym. 2018, 185, 56-62. [CrossRef] [PubMed]

35. Griffiths, R.R.; Woodson, P.P. Reinforcing properties of caffeine: Studies in humans and laboratory animals. Pharmacol. Biochem. Behav. 1988, 29, 419-427. [CrossRef]

36. Bharti, S.K.; Roy, R. Quantitative 1H NMR spectroscopy. Trend Anal. Chem. 2012, 35, 5-26. [CrossRef]

37. Han, L.; Li, P.; Tang, P.; Wang, X.; Zhou, T.; Wang, K.; Ren, F.; Guo, T.; Lu, X. Mussel-inspired cryogels for promoting wound regeneration through photobiostimulation, modulating inflammatory responses and suppressing bacterial invasion. Nanoscale 2019, 11, 15846-15861. [CrossRef]

Sample Availability: Samples of the compounds C are available from the authors. 